
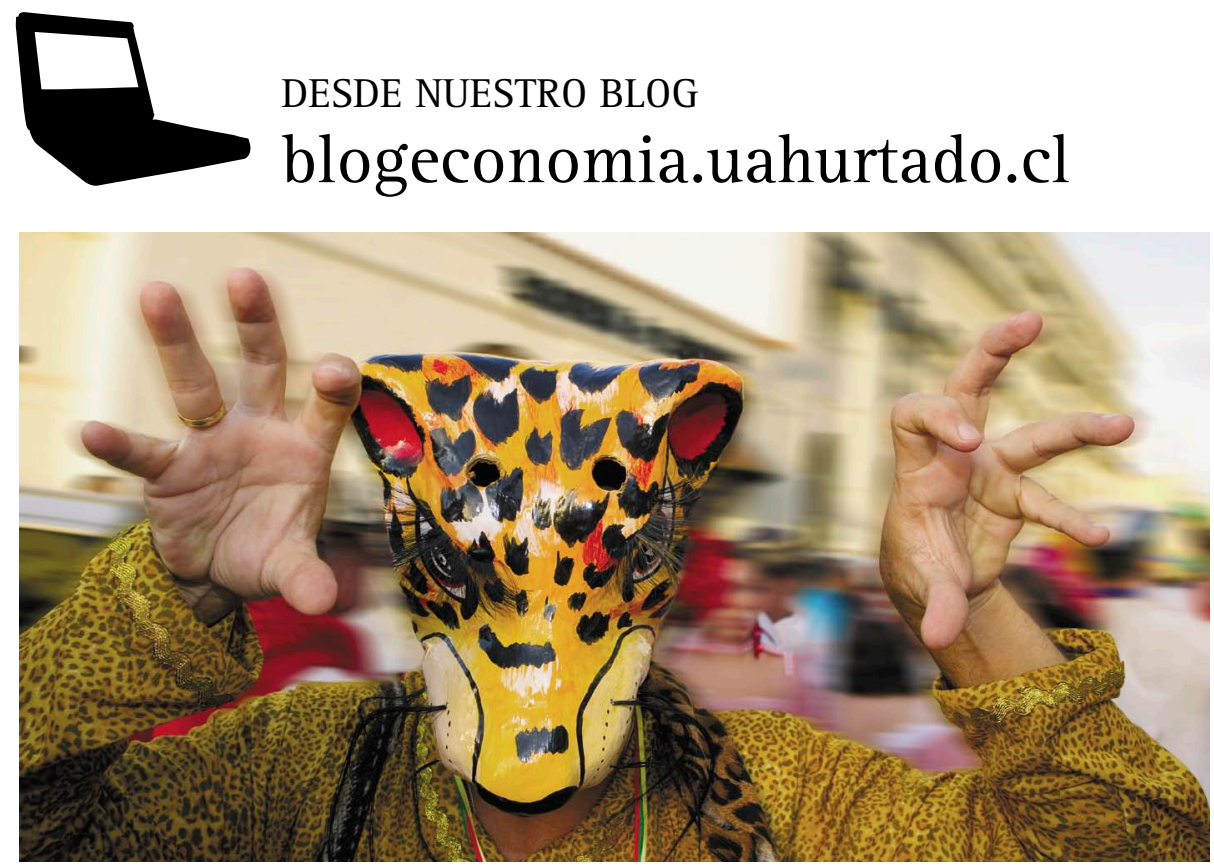

\section{Cómo domar los espíritus animales}

\author{
Por Carlos J. García Toledo*
}

¿Cuál será el desenlace de la crisis financiera internacional en la economía chilena? ¿Implementará la autoridad monetaria medidas no convencionales para enfrentar un escenario cada vez peor, tal como lo han hecho paises desarrollados? ¿Serán medidas excesivamente expansivas, que generen un resurgimiento de la inflación y con ello una recesión posterior por aumento excesivo de las tasas de interés? Muchas dudas. Mucha incertidumbre.

La incertidumbre es justamente el problema. A pesar de que la crisis se ha mostrado a través de varios sintomas, el más importante es un fenómeno relativamente inmaterial que se expresa en las "historias" sobre la falta de confianza de los agentes económicos. Desde Keynes en adelante los economistas han llamado a esto "Ios espiritus animales". En efecto, si las personas fueran perfectamente racionales, entenderian las dimensiones de la crisis y por tanto dirigirian los recursos hacia aquellos sectores económicos líderes de la recuperación. Así, se pasaría de un escenario de crisis a uno de oportunidades. Sin embargo, la realidad no es esa. Por el contrario, las "historias" sobre los efectos de una crisis que se aproxima han provocado decisiones impulsivas que multiplican los daños sobre la economia: posponen planes de inversión, contratación de nuevos trabajadores, provocan una caída en el precio de las acciones y aumentos sistemáticos de la tasa de desempleo.

En este contexto las autoridades deben buscar formas innovadoras para enfrentar a los espiritus animales. Esto evita que la crisis se profundice 0 , por el contrario, que sea menor a lo esperado y, por tanto, tos indeseados de inflación. Una propuesta novedosa es la de los economistas George Akerlof y Robert Shiller, premio Nobel de Economía el primero y reputado economista financiero el segundo. Ellos proponen que los bancos centrales debieran tener como objetivo, además de bajar la inflación, lograr el flujo expedito de crédito al sistema financiero. Esto contrarrestaría "historias" pesimistas porque consumidores y empresarios tendrían recursos frescos para satisfacer sus necesidades de financiamiento. Por el lado fiscal, el Ministerio de Hacienda debería mantenerse flexible para anunciar un nuevo programa si las condiciones lo ameritan, o acotar los efectos del plan ya en marcha. Solo de esta forma los espíritus animales estarán dominados, y no desencadenarán presiones recesivas sin fundamentos ni exagerado optimismo de una recuperación temprana.

* Profesor Economía y Negocios UAH. Ph.D. en Economía, UCLA. terminemos, paradojalmente, con aumen-

\section{el gráfico}

\author{
"¿UN MUNDO AL REVÉS?
}

\author{
Rentabilidad realy \\ riesgo de los multifondos \\ entre abril 08 y marzo 09
}

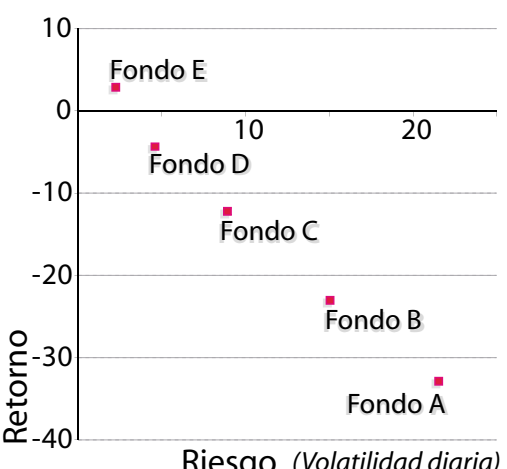

Fuente: Superintendencia de Pensiones

\section{Por Juan Foxley*}

Buena parte de la información que emiten las AFP y la Superintendencia respectiva descansa en la idea de que la toma de riesgos es recompensada con mayores rentabilididades. La idea es correcta y está avalada empíricamente.

Sin embargo, lo que es cierto para períodos largos, puede no serlo para lapsos menores, especialmente cuando, como ocurre hoy, ha reventado una burbuja de precios de activos.

En el periodo indicado en el gráfico, los fondos de pensiones menos volátiles ganan más. Pareciera que, para los fondos riesgosos vale trágicamente aquello de que "no se puede comer bien y dormir bien".

Nadie espera que esta anomalía persista en el largo plazo, pero algún viejo que fue inducido por la ley a quedarse en los Fondos D y E, sonreirá ahora con la frase de Keynes: "A largo plazo todos estamos muertos".

\footnotetext{
* Profesor Facultad EyN, UAH.
} 